\title{
PERBANDINGAN METODE LATIHAN MENGGUNAKAN SATU BOLA DAN DUA BOLA SECARA BERSAMAAN TERHADAP KETERAMPILAN DRIBBLING BOLA BASKET MELEWATI RINTANGAN MENGGUNAKAN TANGAN KANAN DAN KIRI PADA SISWA PUTRA KELAS VII SMP NEGERI 41 PALEMBANG
}

\author{
${ }^{1}$ Sopia Krama Mayasari \\ ${ }^{2}$ Fadlu Rachman \\ ${ }^{3}$ Yunita Lasma Siregar
}

\section{Correspondence: Pendidikan Olahraga Pascasarjana Universitas Negeri Jakarta, Jakarta, Indonesia. \\ E-mail: sopiakrama56@gmail.com, fadlurachman1994@gmail.com}

\begin{abstract}
Abstrak
Perbandingan Metode Latihan Menggunakan Satu Bola dan Dua Bola Secara Bersamaan Terhadap Keterampilan Dribbling Bola Basket Melewati Rintangan Menggunakan Tangan Kanan dan Kiri Pada Siswa Putra Kelas VII SMP Negeri 41 Palembang”. Penelitian ini penelitian eksperimen, yang bertujuan untuk mengetahui perbandingan metode latihan yang lebih efektif untuk meningkatkan keterampilan dribling bola basket, metode latihan satu bola ataukah dua bola secara bersamaan. Berdasarkan hasil analisis data didapat rata-rata pretest kelompok satu bola 25,70 dan kelompok dua bola 25,52, lalu rata-rata posttest didapat kelompok satu bola 23,23 dan kelompok dua bola 23,43. Dari hasil tersebut didapat perbandingan rata-rata pretest dan posttest untuk kelompok satu bola sebesar 2,47 dan dua bola sebesar 2,09. Sedangkan hasil dari analisis varians didapat varians pretest kelompok satu bola 12,30 dan dua bola 10,12, maka didapat Fhitung pretest sebesar 1,21, lalu analisis varians posttest kelompok satu bola 10,36 dan dua bola 11,15, makan F-hitung posttest sebesar 1,07. Sehingga dari hasil analisis data F-hitung posttest 1,07 dan F-tabel didapat 3,14 maka Fhitung 1,07 > Ftabel 3,14 berarti Ha ditolak.
\end{abstract}

\section{Kata Kunci: Bola Basket, Dribbling, Keterampilan}

\section{Pendahuluan}

Permainan bola basket merupakan permainan olahraga beregu yang diperlukan keterampilan individu agar dapat mengimbangi permainan teman satu team dengan baik untuk memudahkan mencetak angka sabanyak-banyaknya agar dapat memenangkan pertandingan. Keterampilan dasar pertama yang harus dimiliki dalam permainan bola basket yaitu dribbling atau menggiring bola. Menurut Danny Kosasih (2008), "dribling pada dasarnya adalah gerakan yang dilakukan sebagai upaya untuk mendekati ring lawan". Keterampilan dribbling sangat penting bagi setiap pemain karena berfungsi agar pemain bisa memasukkan bola ke ring basket, dengan lebih cepat, lebih aman dan peluang memasukkan nilai lebih besar serta bisa menjalankan strategi permainan yang sudah dirancang.

Menurut Marta Dinata (2006) "Kemampuan men-dribble bola dengan tangan lemah dan tangan kuat adalah kunci untuk meningkatkan permainan". Untuk melindungi bola, jagalah agar posisi tubuh agar berada di antara bola dan lawan. Dengan kata lain, jika sedang mendribble dengan sisi tangan yang lemah, maka lindungi dengan tubuh. Untuk kemahirannya dianjurkan dengan 
membiasakan keduanya, jadi yang lebih baik itu hendaknya seimbang dalam kekuatan menggiring dengan tangan kanan maupun tangan kiri. Agar dapat melakukan teknik dribbling bola basket dengan baik maka harus digunakan metode latihan yang tepat dan benar, dalam permainan bola basket ada berbagi macam metode latihan yang dapat digunakan untuk meningkatkan keterampilan dribbling bola basket. Seperti metode latihan dribling bola basket menggunakan satu bola dengan menggunakan tangan kanan dan kiri secara bergantian, lalu metode latihan dribbling dua bola dengan cara mendrible bola secara bersamaan.

Pada usia sekolah siswa dituntut untuk dapat bermain bola basket karena merupakan salah satu olahraga permainan yang tercantum dalam kurikulum, bola basket sudah dikenalkan sejak usia sekolah dasar kelas atas dan dilanjutkan di Sekolah Menengah Pertama. Siswa yang sudah belajar biasanya berkeinginan untuk lebih menguasai agar dapat berprestasi, menurut penulis dalam permainan bola basket pemain yang baik harus bisa menguasai keterampilan dribbling dengan tangan kanan maupun tangan kiri secara seimbang anak yang sudah belajar dan berlatih seharusnya sudah terampil mendribbling bola basket tidak hanya menggunakan satu tangan yang dominan, tetapi pada kenyataannya ratarata anak usia sekolah hingga kelas VIII Sekolah Menengah Pertama salah satunya di SMP Negeri 41 Palembang hanya bisa mendribble bola dengan tangan yang dominan saja, bahkan untuk memindahkan bola dari tangan kanan ke tangan kiri atau sebaliknya sangat sulit dilakukan padahal penguasaan dribble dalam permainan bola basket tangan kanan dan tangan kiri harus seimbang.

Berdasarkan uraian di atas timbul masalah mengapa anak yang sudah lebih dari tiga tahun belajar tetapi masih belum memiliki penguasaan keterampilan dribbling menggunakan tangan kanan dan tangan kiri dengan baik? Atas dasar inilah penulis ingin meneliti lebih dalam lagi mengenai keterampilan dribbling bola basket dengan cara membandingkan dua metode latihan dribbling bola basket yaitu metode latihan satu bola dan metode latihan dua bola.

Bola basket adalah olahraga yang menyenangkan, kompetitif, mendidik, menghibur, dan menyehatkan, Jon Oliver (2007). Bola basket adalah suatu permainan yang dimainkan oleh dua regu yang masing-masing regu terdiri dari 5 orang pemain, jenis permainan ini bertujuan untuk mencari nilai/angka sebanyakbanyaknya dengan cara memasukkan bola ke basket lawan dan mencegah lawan untuk mendapatkan nilai. Dalam memainkan bola, pemain dapat mendorong bola, memukul bola dengan menggunakan telapak tangan terbuka menggiring bola kesegala penjuru dalam lapangan permainan, Muhajir (2006).

Menurut, Hal Wissel (1996), "Bola Basket adalah permainan yang dimainkan oleh 2 tim dengan 5 pemain per tim, bertujuan mendapatkan nilai (skor) dengan memasukkan bola ke keranjang dan mencegah tim lain melakukan hal serupa", dalam permainan bola basket bola hanya dapat diberikan dengan passing atau dengan mendriblenya. Teknik dasar permainan bola basket adalah cara-cara melakukan gerakan memainkan bola, sesuai dengan peraturan yang ditetapkan PERBASI. Teknik bola basket menurut, Muhammad Muhyi (2009) adalah: 1) Melempar dan menangkap bola (passing ball), 2) Memantul-mantulkan bola (dribbling ball), 3) Menembakkan bola ke dalam ring bola basket (shooting).

PJKR_

http://jurnal.unimed.ac.id/2012/index.php/jpehr/index 
Permainan bola basket bola hanya boleh disentuh dengan tangan dan sesuai dengan teknik dasar yang sudah ditetapkan, oleh karena itu keterampilan dribbling dalam permainan bola basket sangat berpengaruh dalam keberhasilan tim untuk memenangkan pertandingan. Dribbling bertujuan untuk memecahkan pertahanan lawan agar mendekat ke basket lawan untuk mencetak angka/poin.

Menurut FIBA (peraturan resmin bola basket internasional) 2010 pada pasal 24.1, Drible adalah gerakan bola hidup yang disebabkan oleh seorang pemain yang sedang menguasai bola dengan melempar, menepis, menggelindingkan bola ke lantai atau dengan sengaja melemparkan bola ke papan pantul. Dribble atau menggiring bola adalah membawa lari bola kesegala arah satu langkah atau lebih dengan ketentuan bola harus dipantulkan ke lantai, baik dengan berjalan maupun berlari dan menggunakan satu tangan, Nuril Ahmadi (2007).

Menurut, Jon Oliver (2004), mendribbe adalah salah satu dasar bola basket yang pertama diperkenalkan kepada para pemain pemula, memantulkan bola mempunyai beberapa fungsi penting dalam permainan bola basket, yakni agar pemain bisa menuju arah ring lawan dengan lebih cepat, lebih aman dan peluang menghasilkan nilai lebih besar. Mendrible bola juga berfungsi untuk melancarkan atau menjalankan strategi permainan yang sudah dirancang sehingga bisa mampu menerobos pola pertahanan yang dikembangkan lawan, Muhammad Muhyi (2009). Dapat disimpulkan bahwa dribble merupakan tehnik dasar yang penting dalam permainan bola basket yang dilakukan dengan memantul-mantulkan bola kelantai menggunakan satu tangan atau dua tangan secara bergantian sebagai upaya menyerang atau menerobos pertahanan lawan untuk menghasilkan angka sebanyak-banyaknya agar memenangkan pertandingan. Jika seseorang pemain ingin memiliki tembakan yang bagus, maka harus ditunjang kemampuan dribble yang sangat bagus juga, baik dribble dengan tangan kanan maupun tangan kiri. Karena kedua teknik dasar tersebut sangat penting, maka harus benar-benar dimiliki oleh seorang pemain bola basket. Oleh karena itu keterampilan dribble baik dengan menggunakan tangan kanan maupun tangan kiri mempunyai peranan penting dalam kemampuan melakukan tembakan dalam permainan bola basket, Marta Dinata (2006). Adapun bentuk-bentuk dribbling menurut pelaksananya dengan menggunakan tangan kiri atau kanan, Nuril Ahmadi (2007) adalah: 1) Dribble rendah, 2) Dribble tinggi, 3) Dribble cepat. 4) Dribble lambat.

Menurut, Marta Dinata (2006), keterampilan dribbling merupakan bagian yang tak terpisahkan dari bola basket dan penting bagi permainan individual dan tim. Cara melakukan keterampilan dribbling yang benar adalah dengan satu tangan saja tetapi harus menguasai kanan maupun kiri. Pada awalnya, bola harus lepas dari tangan sebelum kaki diangkat dari lantai. Adapun cara melakukannya: 1) Pegang bola dengan kedua tangan secara relax, tangan kanan diatas bola, kiri di bawah menjadi tempat terletaknya bola, 2) Berdiri serelax mungkin dengan kaki kiri agak sedikit ke depan dari kaki kanan, 3) Condongkan badan ke depan mulai dari pinggang, 4) Pantulkan bola dengan tangan kanan (pada permukaan bola), 5) Gerakkan lengan hampir seluruhnya, 6) Pantulan bola dilakukan dengan jari-jari tangan dibantu dengan 
pergelangan tangan (bukan memukul dengan telapak tangan), 7) Menjinakan bola dengan sedikit mengikuti gerakannya bola ke atas sebentar dengan jari-jari dan pergelangan tangan, 8) Setelah diratakan, watak, dan irama pantulan (get the feeling) dengan sikap berdiri ditempat maka mulailah dengan maju atau mundur, 9) Menggiring bola dilakukan dengan agak rendah, maju mudur, kiri kanan, berkelok-kelok dengan rintangan dan dengan lawan. Maka dapat disimpulkan bahwa keterampilan dribbling adalah teknik dasar permainan bola basket yang paling terpenting yang dilakukan dengan cara menggiring bola menggunakan tangan kanan maupun tangan kiri secara bergantian tanpa ada kendala apapun

\section{Metode}

Penelitian ini merupakan penelitian eksperimen, yaitu penelitian yang membandingkan sebelum dan sesudah perlakuan (treatment), atau perbandingan dua kelompok sampel, Sugiyono (2007). Adapun rancangan penelitian ini menggunakan rancangan Pretest-Posttest Control Group Design yaitu dua kelompok yang diberikan perlakuan berbeda, tetapi sebelum perlakuan diberikan terlebih dahulu dilakukan tes awal (pretest), kemudian diakhir perlakuan dilakukan tes akhir (posttest). Penelitian ini dilaksanakan di lapangan lingkungan SMP Negeri 41 Palembang. Adapun populasi dalam penelitian ini adalah pada siswa putra kelas VII SMP Negeri 41 Palembang berjumlah 110 siswa putra. Jumlah sampel tersebut diambil dari $60 \%$ populasi yang ada sehingga sample berjumlah 66 sample. Dari 66 sampel yang sudah ada diambil data awal lalu diurutkan dan dijadikan dua kelompok Ordinal-Pairing yaitu; diberi perlakuan latihan satu bola dengan jumlah 33 orang dan 33 orang lagi diberikan perlakuan latihan dua bola.

Teknik pengumpulan data dalam penelitian ini diawali tes awal menggunakan tes dribbling bola basket. Tes yang digunakan adalah dribbling melewati rintangan menggunakan 7 kun, dengan catatan berapa waktu yang didapat untuk melewati rintangan. Tujuan tes ini adalah mengukur kemampuan peserta test dalam dribbling bola basket. Kedua kelompok eksperimen ini diberi perlakuan berupa latihan yang berbeda dengan beban yang sama, latihan satu bola dengan menggunakan pola beranting dan dua bola dengan latihan melewati rintangan. Latihan ini dilakukan selama 6 minggu dengan frekuensi latihan 3 kali seminggu.

Analisis data, dari hipotesis yang diajukan, analisis data dilakuakn dengan menggunakan uji $\mathrm{F}$ guna melihat hasil eksperimen yang menggunakan pre-test dan dan post-test one group design, namun terlebih dahulu dilakukan uji normalitas dan homogenitas. Uji hipotesis menggunakan Uji $F$ pada taraf kepercayaan $\alpha=0,005$ dengan menggunakan rumus sebagai berikut: $\mathrm{Uji}-\mathrm{F}$. 


\section{Pembahasan}

\section{Hasil Pretest Kelompok Dribling Menggunakan Satu Bola}

Berdasarkan hasil Pretest yang terkumpul, kemudian data dianalisis dan dibuat data berkelompok, untuk kemudian dapat dilakukan uji normalitas, homogenitas, dan uji hipotesis. Data hasil Pretest dribbling bola basket kelompok satu bola didapat nilai terendah 20,05 detik dan nilai tertinggi 36,63 detik, maka di dapat rentang 16,58 dengan jumlah kelas sebanyak 6 kelas. Dari hasil pembagian antara rentang dan jumlah kelas maka didapat panjang interval nilai tiap kelas yaitu 2,8. Rata-rata atau mean $\bar{X}$ adalah 25,70, dengan Modus $=26,59$, Median $=$ 25,77, Simpangan Baku $=70,16$, dan Variansnya adalah 12,30.

Tabel 1. Distribusi Frekuensi Hasil Pretest Kelompok Dribbling Mengunakan Satu Bola

\begin{tabular}{ccccccc}
\hline No & Hasil Tes & $\boldsymbol{F}_{\mathbf{1}}$ & $\boldsymbol{X}_{\mathbf{1}}$ & $\boldsymbol{X}_{\mathbf{1}}^{2}$ & $\boldsymbol{F}_{\mathbf{1}} \boldsymbol{X}_{\mathbf{1}}$ & $\boldsymbol{F}_{\mathbf{1}} \boldsymbol{X}_{\mathbf{1}}^{\mathbf{2}}$ \\
\hline $\mathbf{1}$ & $20,05-22,85$ & 8 & 21,45 & 460,1 & 171,6 & 29446,56 \\
\hline $\mathbf{2}$ & $22,86-25,66$ & 8 & 24,26 & 588,54 & 194,08 & 37667,04 \\
\hline $\mathbf{3}$ & $25,67-28,47$ & 11 & 27,07 & 732,78 & 297,77 & 88666,97 \\
\hline $\mathbf{4}$ & $28,48-31,28$ & 5 & 29,88 & 892,81 & 149,4 & 22320,36 \\
\hline $\mathbf{5}$ & $31,29-34,09$ & 0 & 32,69 & 1068,63 & 0 & 0 \\
\hline $\mathbf{6}$ & $34,10-36,9$ & 1 & 35,5 & 1260,25 & 35,5 & 1260,25 \\
\hline & $\sum$ & 33 & & & 848,35 & 179361,2
\end{tabular}

\section{Hasil Pretest Kelompok Dribbling Menggunakan Dua Bola}

Berdasarkan hasil Pretest yang terkumpul, kemudian data dianalisis dan dibuat data berkelompok, untuk kemudian dapat dilakukan uji normalitas, homogenitas, dan uji hipotesis. Data hasil Pretest dribbling bola basket kelompok dua bola didapat nilai terendah 19,32 detik dan nilai tertinggi 31,51 detik, maka di dapat rentang 12,19 dengan jumlah kelas sebanyak 6 kelas. Dari hasil pembagian antara rentang dan jumlah kelas maka didapat panjang interval nilai tiap kelas yaitu 2,03. Rata-rata atau mean $\bar{X}$ adalah 25,52, dengan Modus $=26,76$, Median $=$ 25,81, Simpangan Baku = 59,16, dan Variansnya adalah 10,12.

Tabel 2. Distribusi Frekuensi Hasil Pretest Kelompok Dribbling Menggunakan Dua Bola

\begin{tabular}{ccccccc}
\hline No & Hasil Tes & $\boldsymbol{F}_{\mathbf{1}}$ & $\boldsymbol{X}_{\mathbf{1}}$ & $\boldsymbol{X}_{\mathbf{1}}^{2}$ & $\boldsymbol{F}_{\mathbf{1}} \boldsymbol{X}_{\mathbf{1}}$ & $\boldsymbol{F}_{\mathbf{1}} \boldsymbol{X}_{\mathbf{1}}^{\mathbf{2}}$ \\
\hline $\mathbf{1}$ & $19,32-21,35$ & 4 & 20,33 & 413,30 & 81,32 & 6612,94 \\
\hline $\mathbf{2}$ & $21,36-23,39$ & 5 & 22,37 & 500,41 & 111,85 & 12510,42
\end{tabular}




\begin{tabular}{ccccccc}
\hline $\mathbf{3}$ & $23,40-25,43$ & 6 & 24,41 & 595,84 & 146,46 & 21450,53 \\
\hline $\mathbf{4}$ & $25,44-27,47$ & 8 & 26,45 & 699,60 & 211,6 & 44774,56 \\
\hline $\mathbf{5}$ & $27,48-29,51$ & 7 & 28,49 & 811,68 & 199,43 & 39772,32 \\
\hline $\mathbf{6}$ & $29,52-31,55$ & 3 & 30,53 & 932,08 & 91,59 & 8388,72 \\
\hline & $\sum$ & 33 & & & 842,25 & 133509,49
\end{tabular}

\section{Hasil Posttest Kelompok Dribbling Menggunakan Satu Bola}

Berdasarkan hasil Posttest yang terkumpul kelompok dribbling satu bola, untuk kemudian data dianalisis. Data hasil Posttest dribbling bola basket kelompok dua bola didapat nilai terendah 18,85 detik dan nilai tertinggi 34,60 detik, maka di dapat rentang 15,75 dengan jumlah kelas sebanyak 6 kelas. Dari hasil pembagian antara rentang dan jumlah kelas maka didapat panjang interval nilai tiap kelas yaitu 2,7. Rata-rata atau mean $\bar{X}$ adalah 23,23, dengan Modus $=$ 22,58, Median $=22,79$, Simpangan Baku = 72,96, dan Variansnya adalah 10,36.

Tabel 3. Distribusi Frekuensi Hasil Posttest Kelompok Dribbling Menggunakan Satu Bola

\begin{tabular}{ccccccc}
\hline No & Hasil Tes & $\boldsymbol{F}_{\mathbf{1}}$ & $\boldsymbol{X}_{\mathbf{1}}$ & $\boldsymbol{X}_{\mathbf{1}}^{\mathbf{2}}$ & $\boldsymbol{F}_{\mathbf{1}} \boldsymbol{X}_{\mathbf{1}}$ & $\boldsymbol{F}_{\mathbf{1}} \boldsymbol{X}_{\mathbf{1}}^{\mathbf{2}}$ \\
\hline $\mathbf{1}$ & $18,85-21,55$ & 9 & 20,2 & 408,04 & 181,8 & 33051,24 \\
\hline $\mathbf{2}$ & $21,56-24,26$ & 16 & 22,91 & 524,86 & 366,56 & 134366,23 \\
\hline $\mathbf{3}$ & $24,27-26,97$ & 5 & 25,62 & 565,38 & 128,1 & 16409,61 \\
\hline $\mathbf{4}$ & $26,98-29,68$ & 2 & 28,33 & 802,58 & 56,66 & 3210,35 \\
\hline $\mathbf{5}$ & $29,69-32-39$ & 0 & 31,04 & 963,48 & 0 & 0 \\
\hline $\mathbf{6}$ & $32,40-35,1$ & 1 & 33,75 & 1139,06 & 33,75 & 1139,06 \\
\hline & $\Sigma$ & 33 & & & 766,87 & 188176,49 \\
\hline
\end{tabular}

\section{Hasil Posttest Kelompok Dribbling Menggunakan Dua Bola}

Berdasarkan hasil Posttest yang terkumpul kelompok dribbling dua bola, untuk kemudian data dianalisis. Data hasil Posttest dribbling bola basket kelompok dua bola didapat nilai terendah 17,40 detik dan nilai tertinggi 30,03 detik, maka di dapat rentang 12,63 dengan jumlah kelas sebanyak 6 kelas. Dari hasil pembagian antara rentang dan jumlah kelas maka didapat panjang interval nilai tiap kelas yaitu 2,10. Rata-rata atau mean $\bar{X}$ adalah 23,43, dengan Modus = 23,39 Median $=23,56$, Simpangan Baku $=55$, dan Variansnya adalah 11,15.

Tabel 4. Hasil Posttest Kelompok Dribbling Menggunakan Dua Bola

\begin{tabular}{ccccccc}
\hline No & Hasil Tes & $\boldsymbol{F}_{\mathbf{1}}$ & $\boldsymbol{X}_{\mathbf{1}}$ & $\boldsymbol{X}_{\mathbf{1}}^{2}$ & $\boldsymbol{F}_{\mathbf{1}} \boldsymbol{X}_{\mathbf{1}}$ & $\boldsymbol{F}_{\mathbf{1}} \boldsymbol{X}_{\mathbf{1}}^{2}$ \\
\hline $\mathbf{1}$ & $17,40-19,50$ & 7 & 18,45 & 340,40 & 129,15 & 16679,72
\end{tabular}




\begin{tabular}{ccccccc}
\hline $\mathbf{2}$ & $19,51-21,61$ & 2 & 20,56 & 422,71 & 41,12 & 1690,85 \\
\hline $\mathbf{3}$ & $21,62-23,72$ & 8 & 22,67 & 573,92 & 181,36 & 32891,44 \\
\hline $\mathbf{4}$ & $23,73-25,83$ & 7 & 24,78 & 614,04 & 173,46 & 30088,37 \\
\hline $\mathbf{5}$ & $25,84-27,94$ & 6 & 26,89 & 2892,28 & 161,34 & 26030,59 \\
\hline $\mathbf{6}$ & $27,95-30,05$ & 3 & 29 & 841 & 87 & 7569 \\
\hline & 5 & 33 & & & 733,43 & 114949,97 \\
\hline
\end{tabular}

Dari hasil pengolahan data uji Normalitas diperoleh angka normalitas distribusi data seperti tabel dibawah ini:

Tabel 5. Hasil Pengujian Normalitas Data

\begin{tabular}{clccc}
\hline \multirow{2}{*}{ Pre Test } & Data & N & Km & ket \\
& Dribble Satu Bola & 33 & $-0,012$ & Normal \\
\cline { 2 - 5 } & Dribble Dua Bola & 33 & $-0,02$ & Normal \\
\hline \multirow{2}{*}{ Post Test } & Dribble Satu Bola & 33 & 0,008 & Normal \\
\cline { 2 - 5 } & Dribble Dua Bola & 33 & 0,0007 & Normal
\end{tabular}

Dapat disimpulkan bahwa data kelompok satu bola dan dua bola berdistribusi normal, karena hasil kemiringan $(\mathrm{km})$ kelompok satu bola dan kelompok dua bola terletak di antara (1) dan $(+1)$, maka data tersebut berdistribusi normal. Uji homogenitas dilakukan untuk melihat untuk melihat apakah data penelitian memiliki varians yang sama (homogen) atau tidak. Hasil analisis data diperoleh homogenitas sebagai beikut:

Tabel 6. Hasil Uji Homogenitas Varians

\begin{tabular}{ccccc}
\hline Data & N & $\mathbf{X}^{2}$ hitung & $\mathbf{X}^{2}$ tabel & Ket \\
\hline $\begin{array}{c}\text { Tes Awal (pretest) } \\
\text { Dan }\end{array}$ & 66 & 0,30 & 3,84 & Homogen
\end{tabular}

Tes Akhir (Posttest)

Dari data yang diperoleh diatas maka, dengan taraf kepercayaan $a=0,05$ diperoleh $\mathrm{X}^{2} \mathrm{t}_{\text {abel }}=3,84$ dan $\mathrm{X}^{2}$ hitung $=0,30$ hingga dapat ditulis: $0,30<3,84$ dengan syarat homogen $=X^{2}$ hitung $<X^{2}$ tabel, jadi dapat disimpulkan bahwa sampel tersebut dari populasi yang sama (Homogen).

Berdasarkan data pada tabel perbandingan Pretest dan Posttest dribbling bola basket kelompok satu bola dapat di lihat bahwa pada Pretest di dapat rata-rata 25,70, kemudian pada Posttest di dapat rata-rata 23,23, maka diketahui adanya perbandingan sebesar 2,47. Jadi Posttest lebih baik di bandingkan Pretest.

Sedangkan data pada tabel perbandingan Pretest dan Posttest dribbling bola basket kelompok dua bola dapat di lihat bahwa pada Pretest di dapat rata-rata

PJKR_

http://jurnal.unimed.ac.id/2012/index.php/jpehr/index 
25,52, kemudian pada Posttest di dapat rata-rata 23,43, maka diketahui adanya perbandingan sebesar 2,09. Jadi Posttest lebih baik di bandingkan Pretest.

Berdasarkan perbandingan di atas antara kelompok satu bola dan dua bola, yaitu kelompok satu bola dengan perbandingan rata-rata Pretest dan Posttest sebesar 2,47 dan kelompok dua bola dengan perbandingan rata-rata Pretest dan Posttest sebesar 2,09. Maka terjadi selisih sebesar 0,38 lebih besar kelompok dribbling menggunakan satu bola.

Berdasarkan hasil analisis varians yang dihitung, varians pretest kelompok satu bola sebesar 12,30 dan varians pretest kelompok dua bola sebesar 10.12. Maka didapat F-hitung pretest sebesar 1,21. Sedangkan berdasarkan hasil analisi varians posttest yang dihitung, didapat varians posttest kelompok satu bola sebesar 10,36 dan varians kelompok dua bola sebesar 11,15. Jadi didapat F-hitung posttest sebesar 1,07. Sehingga dari analisis data Fhitung posttest 1,07 dan F-tabel didapat 3,14 maka Fhitung 1,07 > Ftabel 3,14 berarti Ha ditolak dan hasil tidak signifikan.

Perbandingan diatas membuktikan bahwa dari hasil rata-rata posttest dan analisis varians kelompok satu bola dan kelompok dua bola diketahui metode latihan dribbling menggunakan dua bola lebih baik di bandingkan metode latihan dribbling menggunakan satu bola.

\section{Simpulan}

Berdasarkan hasil penelitian dan pembahasan dapat dikemukakan disimpulkan bahwa ada perbandingan antara metode latihan dribbling menggunakan satu bola dan dua bola terhadap keterampilan dribbling bola basket tetapi tidak signifikan. dari hasil penelitian ini ternyata metode latihan dribbling dengan dua bola itu lebih baik hasilnya dibandingkan dengan metode latihan satu bola. perbandingan rata-rata Pretest dan Posttest sebesar 2,47 dan kelompok dua bola dengan perbandingan rata-rata Pretest dan Posttest sebesar 2,09. Maka terjadi selisih sebesar 0,38 lebih besar kelompok dribbling menggunakan satu bola.

\section{Rujukan}

Ahmad, Maskur, 2006. Kinesiologi Olahraga. Palembang: Noerfikri

Ahmadi, Nuril, 2007. Permainan Bola Basket. Solo: Era Intermedia

Bompa, T.O, 1995. Theory and Methodology of Training. New York: Kendall Hunt Publ. Company

Dinata, Marta, 2006. Konsep \& Teknik Permainan Bola Basket. Jakarta: Cerdas Jaya

Djoko P, 2006. Ilmu Kepelatihan. Yogyakarta: FKIP UNY

Harsono, 2005. Manusia dan Olahraga. Bandung: ITB dan FPOK/IKIP

Keven, 2007. Permainan Bola Bakset. Yogyakarta: PT. Citra Aji Parama

Kosasih, Denny, 2010. Fundamental Bola Basket. Jakarta: Akademika Pressindo

Kosasih, Engkos, 1984. Olahraga Teknik dan Program Latihan. Jakarta: Akademika Pressindo

Muhajir, 2006. Pendidikan Jasmani Olahraga dan Kesehatan. Jakarta: Erlangga

PJKR_

http://jurnal.unimed.ac.id/2012/index.php/jpehr/index 
Muhyi, Muhammad, 2009. Meningkatkan Kebugaran Jasmani Melalui Permainan dan Olahraga Bola Basket. Surabaya: PT. Grasindo

Nurhasan, 2001. Tes dan Pengukuran Dalam Pendidikan Jasmani. Jakarta: Direktorat Jenderal Olahraga

Oliver, Jon, 2007. Dasar-Dasar Bola Basket. Bandung: Pakar Raya, Peraturan Resmi Bola Basket 2010 (FIBA)

Sugiyono, 2007. Metodelogi Penelitian Kuantitatif Kualitatif dan R\&D. Bandung: ALFABETA

Sudjana, 2002. Metoda Statistika. Bandung: PT. TARSITO

Suharsimi, 2006. Prosedur Penelitian. Jakarta: CV. Rineka Cipta

Sukadiyanto, 2011. Pengantar Teori dan Metodelogi Melatih Fisik. Bandung: CV. Lubuk Agung

Wissel, Hall, 1996. Bola Basket. Jakarta: PT. Raja Grafindo Persada 